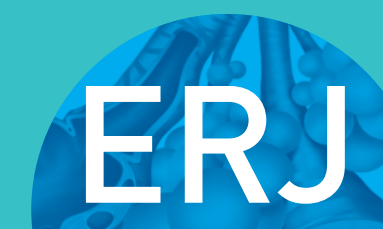

open research
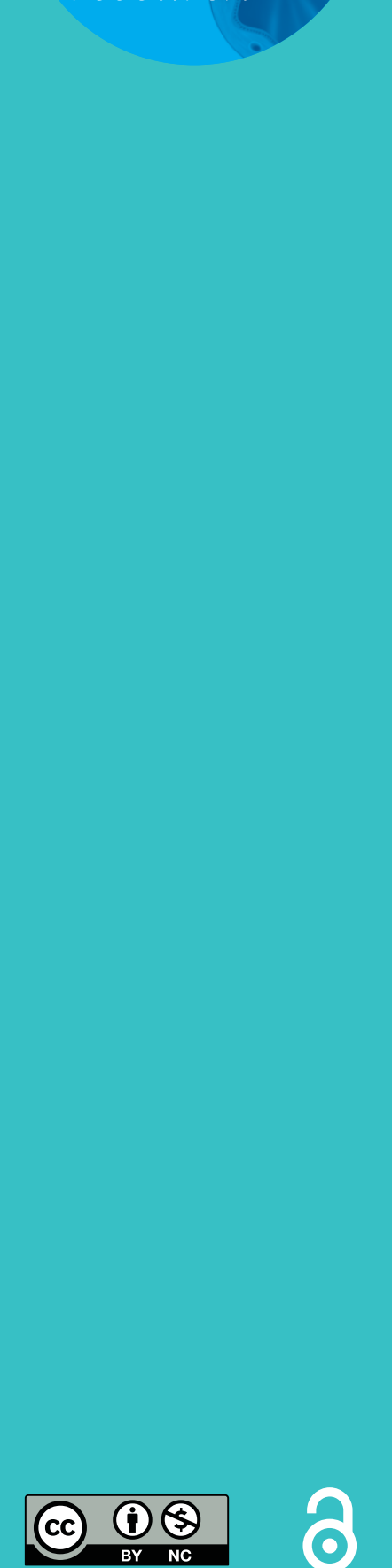

\section{Attitudes and preferences of home mechanical ventilation users from four European countries: an ERS/ELF survey}

\author{
Sarah Masefield ${ }^{1}$, Michele Vitacca², Michael Dreher ${ }^{3}$, Michael Kampelmacher $^{4}$, \\ Joan Escarrabill ${ }^{5}$, Mara Paneroni ${ }^{2}$, Pippa Powell ${ }^{1}$ and Nicolino Ambrosino ${ }^{6}$
}

Affiliations: ${ }^{1}$ European Lung Foundation, Sheffield, UK. ${ }^{2}$ Respiratory Rehabilitation Division, Istituti Clinici Scientifici Maugeri IRCCS, Lumezzane, Italy. ${ }^{3}$ Division of Pneumology, University Hospital Aachen, Aachen, Germany. ${ }^{4}$ Home Ventilation Service, University Medical Center Utrecht, Utrecht, the Netherlands. ${ }^{5}$ Hospital Clinic de Barcelona, Master Plan for Respiratory Diseases (Ministry of Health) and Health Services Research on Chronic Patients Network (REDISSEC), Barcelona, Spain. ${ }^{6}$ Pulmonary and Respiratory Medicine Dept, Medical Faculty Sebelas Maret University, Solo, Indonesia.

Correspondence: Nicolino Ambrosino, Via di Montenero 138, 57128 Livorno, Italy. E-mail: nico.ambrosinol gmail.com

ABSTRACT Home mechanical ventilation is increasingly used by people with chronic respiratory failure. However, there are few reports on attitudes towards treatment.

A web-based survey in eight languages was disseminated across 11 European countries to evaluate the perception of home mechanical ventilation provision in ventilator-assisted individuals and caregivers.

Out of 787 responders from 11 European countries, 687 were patients and 100 were caregivers. 95\% of patients and $94 \%$ of caregivers were from only 4 countries (Germany, the Netherlands, Italy, Spain). The majority of respondents were male and aged 46-65 years. Obstructive lung diseases were proportionally more represented among respondent patients (46\%), and neuromuscular diseases (65\%) were more represented among patients of respondent caregivers. About $20 \%$ of respondent patients and caregivers were not sure of the modality of ventilation. Different interfaces were used, with a minority of respondents in all countries using invasive home mechanical ventilation by tracheostomy.

These results may be useful for healthcare providers and policy makers to improve the quality of patients' daily lives.

$@$ ERSpublications

An @ERStalk/@EuropeanLung survey of European ventilator users http://ow.ly/u5e130csNFs

Cite this article as: Masefield S, Vitacca M, Dreher M, et al. Attitudes and preferences of home mechanical ventilation users from four European countries: an ERS/ELF survey. ERJ Open Res 2017; 3: 00015-2017 [https://doi.org/10.1183/23120541.00015-2017].

This article has supplementary material available from openres.ersjournals.com

Received: Feb 082017 | Accepted after revision: May 172017

Conflict of interest: S. Masefield and P. Powell were employed by the European Lung Foundation during the conduct of this study. Other disclosures can be found alongside this article at openres.ersjournals.com

Copyright $\odot$ ERS 2017. This article is open access and distributed under the terms of the Creative Commons Attribution Non-Commercial Licence 4.0. 


\section{Introduction}

Long-term home mechanical ventilation (HMV) is increasingly used by people with chronic respiratory failure (CRF) arising from advanced diseases such as chronic obstructive pulmonary disease (COPD), restrictive thoracic disease (RTD) and neuromuscular disease (NMD). The last reported (although probably underestimated) prevalence of European patients requiring HMV is 6.6 per 100000 population [1]. More recent Canadian data report a 12.9 per 100000 prevalence [2], while other surveys report prevalences of 9.9 and 12.0 per 100000 in Australia and New Zealand, respectively [3], and 23 per 100000 in Catalonia [4].

Although HMV has been shown to reduce patients' symptoms, improve health-related quality of life (HRQL) and, in many cases, reduce mortality and hospitalisations $[5,6]$, there are problems in providing HMV, such as patient and caregiver compliance and training, reimbursement policies, patient/family involvement and resources [7]. Additional factors such as the technology required and the need for professional supervision make the management of ventilator users a difficult task. Supervision by external companies may result in a lack of standardisation or regular feedback to the prescribing centres, as well as increasing costs and logistical problems $[8,9]$. There are also differences in end-of-life decisions between northern and southern European countries [10]. Differences in availability, awareness, reimbursement policies and adherence to evidence-based medical policies/indications may also lead to wide variations in prevalence and in the patterns of HMV provision throughout different European countries [1, 8]. Few national reports have described attitudes towards treatment in ventilator users [11-13], including patients and caregivers, and there have been none across Europe.

A Task Force established by the European Respiratory Society (ERS) produced a statement on the tele-monitoring of ventilator-assisted individuals [14]. To support this Task Force, a survey was co-produced and promoted by the European Lung Foundation (ELF) to evaluate users' perception of HMV provision across European countries. In the present study, we report on the results on the perception of ventilator users of 11 European countries regarding several aspects of their management.

\section{Methods}

The study was approved by the Ethical Committee of the Salvatore Maugeri Foundation (1006/2014).

The literature search was performed in the frame of the above ERS Task Force [14]. Members of the Task Force searched EMBASE, CINALH, PubMed, PsychINFO and Scopus data bases using the following keywords: ventilator-dependent, tele-monitoring, home mechanical ventilation, sleep disorders, respiratory tele-medicine, tele-monitoring AND end of life. Papers published between 2003 and 2015 in English language were considered. Members assessed the identified studies for appropriateness. Among 2975 papers, 150 were considered appropriate for analysis.

A web-based descriptive questionnaire was developed after a literature review. The online format enabled rapid and wide-reaching dissemination of the questionnaire across Europe. The draft was reviewed by a small working group of ventilator users to ensure the validity of the content and accessibility in terms of language and format. The questionnaire was open online from April 14, 2014 to March 22, 2015.

Using the Eurovent survey [1] disease categories, the questionnaire was sent to HMV users with: 1) NMD: muscular dystrophies, motor neuron disease (including amyotrophic lateral sclerosis and spinal muscular atrophy), central hypoventilation, spinal cord damage and phrenic nerve paralysis; 2) RTD: early-onset kyphoscoliosis, tuberculosis and lung resection sequelae; and 3) Lung and airway diseases (Lung): COPD, cystic fibrosis, bronchiectasis, pulmonary fibrosis. Respondents who specified sleep apnoea or obesity hypoventilation syndrome as the sole underlying cause of HMV were excluded.

The 45-item questionnaire explored four areas: 1) patients' demographic and clinical characteristics; 2) issues influencing compliance, such as interface comfort, possibilities of travelling, sleeping and socialising with a ventilator, type and technical functioning of the ventilator (e.g. alarms, ability to operate and change settings, on/off switches and electricity consumption); 3) support and training and education; and 4) requests for improved devices and support.

Caregiving was defined as follows. 1) Formal: provided by a nursing or home-care team or a personal assistant paid by the healthcare system or patient's insurance, etc. 2) Informal: provided by partners/ spouses and/or friends who are not professional $[15,16]$.

The questionnaire was available online in eight languages (English, German, Dutch, Spanish, Italian, Portuguese, Greek and French). Full details of the aim of the questionnaire, anonymity and contact details for the ELF were provided at the start of the questionnaire, with implied consent given by each respondent [17]. The data collected were anonymous, although respondents could choose to leave an e-mail address to receive updates on the project. No maximum or minimum number of responses for language or country 
was set. Open responses were translated into English, and thematic analysis was conducted. The survey was disseminated via the Task Force members, ERS and ELF professional and patient networks, and the ELF website, newsletter and social media (Twitter and Facebook). This snowball sampling approach sought

\section{TABLE 1 Patient demographic and home mechanical ventilation characteristics}

\begin{tabular}{|c|c|c|}
\hline & Patients & Caregivers \\
\hline Responders $\mathrm{n}$ & 687 & 100 \\
\hline \multicolumn{3}{|l|}{ Countries $\mathbf{n}$} \\
\hline UK & 16 & 5 \\
\hline Ireland & 5 & 0 \\
\hline Germany & 238 & 16 \\
\hline Netherlands & 256 & 30 \\
\hline Portugal & 5 & 1 \\
\hline Italy & 97 & 38 \\
\hline Spain & 65 & 10 \\
\hline Belgium & 1 & 0 \\
\hline France & 2 & 0 \\
\hline Czech Republic & 1 & 0 \\
\hline Greece & 1 & 0 \\
\hline Males & $58 \%$ & $44 \%$ \\
\hline \multicolumn{3}{|l|}{ Age } \\
\hline$<18$ years & $1 \%$ & $3 \%$ \\
\hline $18-35$ years & $9 \%$ & $14 \%$ \\
\hline $36-45$ years & $8 \%$ & $14 \%$ \\
\hline 46-65 years & $43 \%$ & $43 \%$ \\
\hline $66-75$ years & $27 \%$ & $13 \%$ \\
\hline$>75$ years & $12 \%$ & $13 \%$ \\
\hline \multicolumn{3}{|l|}{ Time of ventilator use } \\
\hline $0-6$ months & $11 \%$ & $5 \%$ \\
\hline $6-12$ months & $8 \%$ & $16 \%$ \\
\hline $1-2$ years & $12 \%$ & $23 \%$ \\
\hline $2-5$ years & $24 \%$ & $22 \%$ \\
\hline $5-10$ years & $21 \%$ & $20 \%$ \\
\hline$>10$ years & $24 \%$ & $14 \%$ \\
\hline \multicolumn{3}{|l|}{ Interface } \\
\hline Mouth mask/mouth piece & $34 \%$ & $30 \%$ \\
\hline Nasal mask & $39 \%$ & $36 \%$ \\
\hline Negative pressure device & $0 \%$ & $0 \%$ \\
\hline Tracheotomy & $11 \%$ & $10 \%$ \\
\hline Full face mask & $10 \%$ & $11 \%$ \\
\hline Mouthpiece & $4 \%$ & $8 \%$ \\
\hline Nasal pillows & $2 \%$ & $5 \%$ \\
\hline \multicolumn{3}{|l|}{ Home support } \\
\hline Partner/spouse & $29 \%$ & $31 \%$ \\
\hline Relative & $14 \%$ & $34 \%$ \\
\hline Friend & $3 \%$ & $0 \%$ \\
\hline Support worker/personal assistant & $6 \%$ & $12 \%$ \\
\hline Nurse/home support team & $14 \%$ & $18 \%$ \\
\hline Self/independent & $19 \%$ & $2 \%$ \\
\hline Receiving support of two or more types & $15 \%$ & $3 \%$ \\
\hline \multicolumn{3}{|l|}{ Time of ventilator use } \\
\hline Daytime & $44 \%$ & $65 \%$ \\
\hline Night time & $89 \%$ & $92 \%$ \\
\hline Daytime h & 6 & 7.2 \\
\hline Night time $\mathrm{h}$ & 8 & 9.8 \\
\hline \multicolumn{3}{|l|}{ Ventilation modalities } \\
\hline Not sure & $20 \%$ & $21 \%$ \\
\hline Bilevel & $33 \%$ & $33 \%$ \\
\hline Volume-cycled ventilator & $7 \%$ & $4 \%$ \\
\hline Pressure support ventilator & $8 \%$ & $8 \%$ \\
\hline Combination or multimode & $13 \%$ & $19 \%$ \\
\hline Other & $19 \%$ & $15 \%$ \\
\hline
\end{tabular}


to reach the maximum number of potential questionnaire respondents, but made it impossible to record the number aware of the questionnaire and who chose not to respond [18]. The findings were validated by the consistencies between the sample and the wider European HMV population, thus giving reliability and generalisability to the findings. Preliminary and qualitative results have been summarised in an internal ERS publication and presented at the 2016 ERS annual meeting $[19,20]$.

\section{Statistical analysis}

The data from the survey were recorded and summarised as percentage for dichotomous or categorical variables. Data were analysed according to the respondents (patients and caregivers).

\section{Results}

In total, 912 individuals answered the survey, and 125 responses were excluded because they were from non-European countries or the responses were incomplete. Out of 787 respondents from 11 European countries, 687 were patients and 100 were caregivers. 95\% of patients and $94 \%$ of caregivers were from only 4 countries (Germany, Netherland, Italy and Spain). Patients' demographic, geographic, ventilator and home support characteristics, as reported by ventilator-assisted individuals (VAIs) and caregivers from all 11 countries, are presented in table 1 . The majority of respondent patients were male, and the majority of responding caregivers' patients were female, the majority of both being aged 46-65 years. In each of the countries, the patients were using ventilation for an average of $\geqslant 4 \mathrm{~h}$ during the day and $\geqslant 8 \mathrm{~h}$ at night.

Diseases underlying the need for HMV are shown in figure 1. Lung diseases were proportionally more represented among respondent patients (46\%) whereas NMD (65\%) were more represented among patients of respondent caregivers.

Most patients used the bilevel modality and about $20 \%$ of both patients and, rather surprisingly, caregivers were not sure about the ventilator modality (table 1). A range of interfaces were used, with oro-nasal masks and mouthpieces being largely more represented. A minority of patients in all countries used invasive HMV by tracheostomy (table 1). As expected, caregivers did not respond on behalf of independent patients using their own ventilator. Relatives including partners and spouses were the primary support for the majority of patients at home (43\%) (table 1).

Technical aspects related to HMV are shown in tables 2 and 3. There were no differences between the answers of patients and caregivers. Some aspects were highly ranked in all countries, with all aspects being identified as important or very important. For example, the highest ranked everyday aspects were smooth "natural feeling" breathing, being able to fall asleep and stay asleep while using the ventilator, and how comfortable the mask is. Similarly, there was agreement on the most important technical aspects: being able to change and clean tubing and filters and for the ventilator to respond automatically to breathing. Other issues were not considered as important or very important by the majority of respondent patients and caregivers.

In all countries, the most common form of communicating information on ventilator use between healthcare professional and patient was spoken information, followed by equipment demonstration and having someone watch them use the equipment to check if they were using it correctly. Other means of information acquisition included self-study, such as reading online and using a $\mathrm{CD}$, and learning through using the device i.e. practice. In each country, respondents had, on average, received information in more

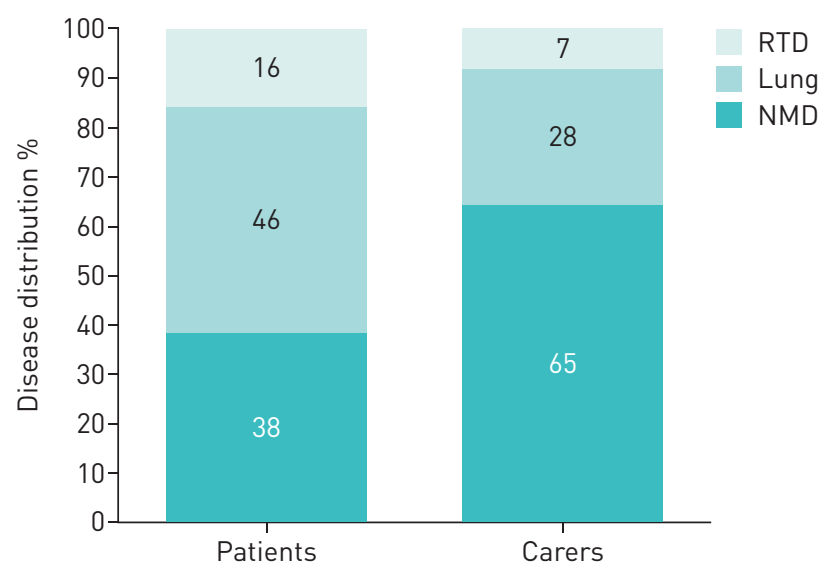

FIGURE 1 Diseases leading to home mechanical ventilation. RTD: restrictive thoracic disease; NMD: neuromuscular disease. 


\begin{tabular}{|c|c|c|c|c|c|}
\hline & Patients & Caregivers & & Patients & Caregivers \\
\hline How comfortable the mask is & & & Reducing nasal secretions & & \\
\hline Unimportant & $0 \%$ & $3 \%$ & Unimportant & $5 \%$ & $2 \%$ \\
\hline Not very important & $2 \%$ & $1 \%$ & Not very important & $17 \%$ & $19 \%$ \\
\hline Not relevant & $10 \%$ & $24 \%$ & Not relevant & $17 \%$ & $13 \%$ \\
\hline How noisy the ventilator is & & & Not feeling claustrophobic & & \\
\hline Unimportant & $5 \%$ & $3 \%$ & Unimportant & $14 \%$ & $6 \%$ \\
\hline Not very important & $12 \%$ & $16 \%$ & Not very important & $14 \%$ & $17 \%$ \\
\hline Important & $34 \%$ & $36 \%$ & Important & $19 \%$ & $21 \%$ \\
\hline Very important & $45 \%$ & $42 \%$ & Very important & $30 \%$ & $36 \%$ \\
\hline Very important & $30 \%$ & $52 \%$ & Very important & $33 \%$ & $45 \%$ \\
\hline Not relevant & $23 \%$ & $4 \%$ & Not relevant & $10 \%$ & $11 \%$ \\
\hline How heavy the ventilator is & & & How big the ventilator is & & \\
\hline Unimportant & $10 \%$ & $18 \%$ & Unimportant & $8 \%$ & $11 \%$ \\
\hline Not very important & $25 \%$ & $22 \%$ & Not very important & $20 \%$ & $31 \%$ \\
\hline Important & $31 \%$ & $30 \%$ & Important & $37 \%$ & $27 \%$ \\
\hline Very important & $26 \%$ & $21 \%$ & Very important & $28 \%$ & $25 \%$ \\
\hline Not relevant & $8 \%$ & $9 \%$ & Not relevant & $7 \%$ & $6 \%$ \\
\hline
\end{tabular}

than one way. Issues related to satisfaction with home support, training and education are shown in table 4 . The respondents were positive about the support received at home.

\section{Discussion}

Several developments have improved the management of patients with HMV [21]. These include more portable and easier-to-use ventilators [22], increased availability of home services, the pressure to open intensive care unit beds to serve more unstable patients, and improved access to information and training on HMV [10, 23]. A few reports have described the attitudes of ventilator users about their treatment [11-13]. However, to the best of our knowledge, this is the first survey evaluating these issues in different European countries. The information submitted in the anonymous questionnaire was considered truthful, as there was no incentive for inaccurate reporting [15]. Furthermore, the responses are consistent with the literature on the characteristics of HMV users in Europe $[1,8]$ and show good internal consistency.

In our survey, formal support was very variable among different European countries. This may reflect differences in the organisation and resources of countries health systems. Family members are essential for enabling patients to live at home under mechanical ventilation. Formal caregivers may include individuals "who provide personal care or other supportive services, other than a relative or friend". Caregiver services range from intimate care such as dressing, bathing and feeding, to more impersonal services such as house cleaning, meal preparation, financial management and transportation [24]. When accepting their family member at home, informal caregivers may have a very limited understanding of their underlying diagnosis and rate of disease progression, thereby underestimating the potential caregiver burden [25].

A higher number of caregivers were supporting a greater number of patients with NMD (figure 1) and this was reflected in the greatest number of ventilator users for $>10$ years and with more respondents in the younger age category. This is not surprising, as NMD patients are usually associated with higher levels of dependence than those suffering from COPD. The use of long-term non-invasive ventilation (NIV) in stable COPD patients is still under debate [5, 26]. Despite the fact that not all clinical guidelines recommend the routine use of long-term NIV in stable COPD patients with CRF [27-30], it is common practice in some countries, and this group accounts for approximately one-third of users in Europe [1]. Moreover, a recent international web survey among specialists dealing with NIV domiciliary programmes examined patterns of use in these patients. Reduction in hospital admissions, improvement in HRQL and relief of dyspnoea were considered the main expected benefits [31]. 


\section{TABLE 3 Technical issues}

\section{Patients Caregivers}

Being able to fall asleep easily and stay asleep whilst using my ventilator

Unimportant

Not very important

Important

Very important

Not relevant

Being able to travel with it (e.g. by car and air)

Unimportant

Not very important

Important

Very important

Not relevant

Having alarms

Unimportant

Not very important

Important

Very important

Not relevant

How much electricity it uses

Unimportant

Not very important

Important

Very important

Not relevant

Having a built-in/integrated humidifier

Unimportant

Not very important

Important

Very important

Not relevant

The ventilator compensates for mask leaks

Unimportant

Not very important

Important

Very important

Not relevant

Being able to adjust the settings

Unimportant

Not very important

Important

Very important

Not relevant

Being able to clean the equipment easily

Unimportant

Not very important

Important

Very important

Not relevant

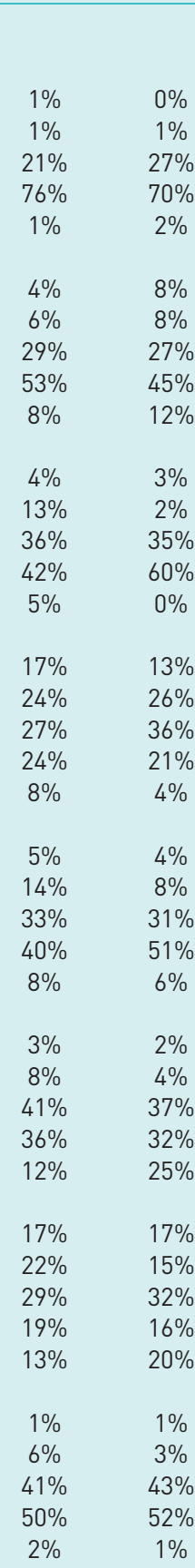

Patients Caregivers

Being able to mount it on my wheelchair

Unimportant

Not very important

Important

Very important

Not relevant

$11 \% \quad 4 \%$

$8 \% \quad 10 \%$

$15 \% \quad 25 \%$

$29 \% \quad 41 \%$

$37 \% \quad 20 \%$

The ventilator responds automatically to my breathing

Unimportant

Not very important

Important

Very important

Not relevant

Being able to adjust the alarms

Unimportant

Not very important

Important

Very important

Not relevant

Having an external power supply

Unimportant

Not very important

Important

Very important

Not relevant

Having a battery with a long life

Unimportant

Not very important

Important

Very important

Not relevant

Being able to operate the ventilator myself

$2 \% \quad 0 \%$

$3 \% \quad 3 \%$

$31 \% \quad 31 \%$

$60 \% \quad 62 \%$

$4 \% \quad 4 \%$

$7 \% \quad 11 \%$

$16 \% \quad 12 \%$

$38 \% \quad 42 \%$

$30 \% \quad 33 \%$

$9 \% \quad 2 \%$

$7 \% \quad 2 \%$

$15 \% \quad 9 \%$

$33 \% \quad 23 \%$

$34 \% \quad 57 \%$

$11 \% \quad 9 \%$

$6 \% \quad 2 \%$

$11 \% \quad 7 \%$

$32 \% \quad 30 \%$

$41 \% \quad 56 \%$

$10 \% \quad 5 \%$

(e.g. on/off buttons, alarm reset)

Unimportant

Not very important

Important

Very important

Not relevant

Having more than one pre-programmed setting

Unimportant

Not very important

Important

Very important

Not relevant

Being able to change/clean the tubing and

filters easily

Unimportant

Not very important

Important

Very important

Not relevant
$4 \% \quad 7 \%$

$5 \% \quad 6 \%$

$31 \% \quad 36 \%$

$53 \% \quad 37 \%$

$7 \% \quad 14 \%$

$14 \% \quad 13 \%$

$18 \% \quad 6 \%$

$32 \% \quad 41 \%$

$22 \% \quad 24 \%$

$14 \% \quad 16 \%$

$0 \% \quad 1 \%$

$3 \% \quad 2 \%$

$41 \% \quad 33 \%$

$55 \% \quad 63 \%$

$1 \% \quad 1 \%$

The most frequently identified type of ventilator for all countries was bilevel, reflecting the preference for these ventilators as they are smaller, less expensive and easier to use than other conventional ventilators, including volume-cycled, pressure support or combination $[1,22]$.

The respondents were positive about the support received at home. The Canadian survey [2] estimated a VAI prevalence of 12.9 per 100000 population, with $73 \%$ receiving NIV. Services were delivered by 39 


\section{TABLE 4 Home support and training}

\section{Patients Caregivers}

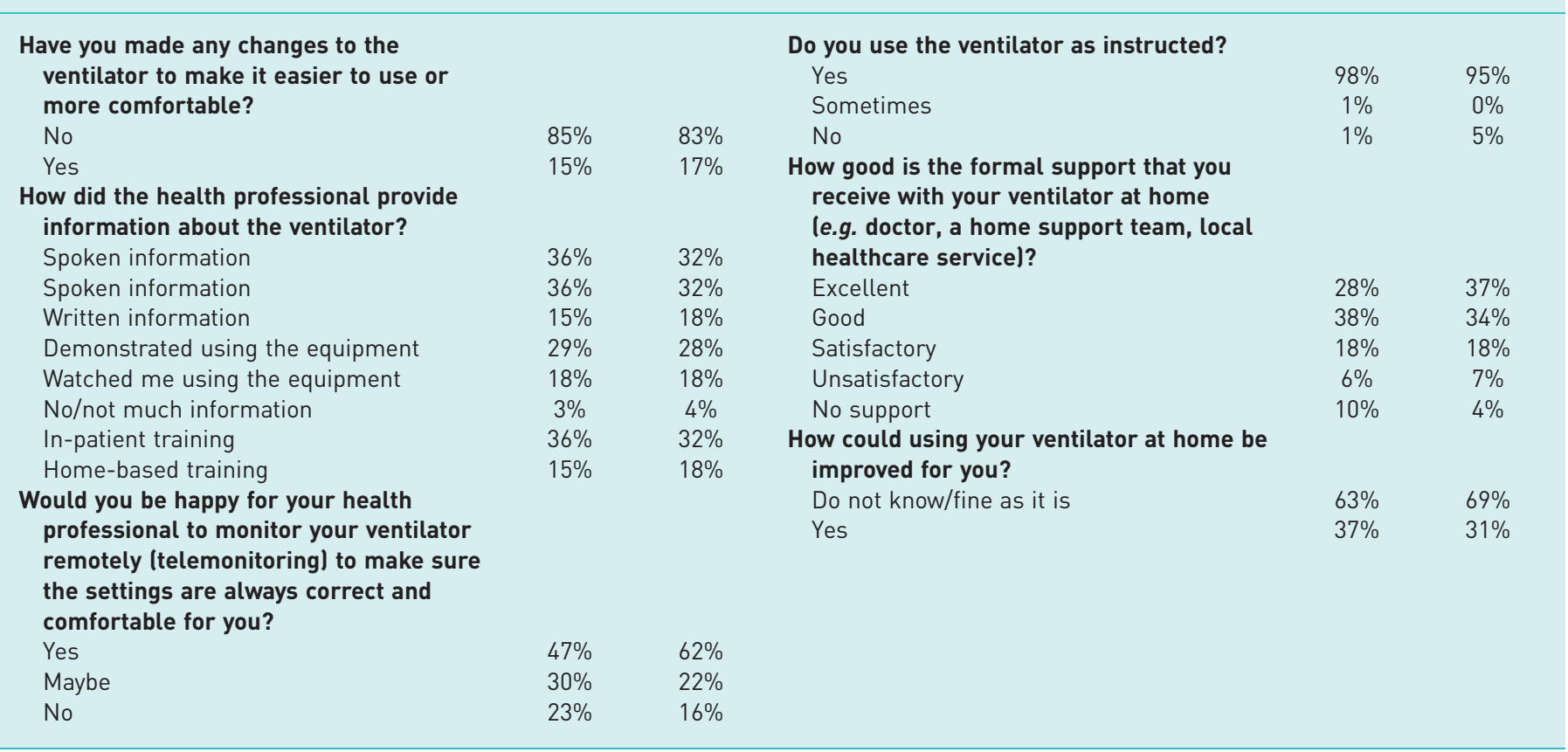

institutional providers and 113 community providers. Most providers stated that caregiver competency was a prerequisite for home discharge. Important barriers to home transition were considered: insufficient funding for paid caregivers, equipment and supplies; a shortage of paid caregivers; and negotiating public funding arrangements. ViTACCA et al. [32] evaluated factors for greater care burden. The underlying disease, the level of dependency, hours spent under mechanical ventilation, tracheotomy, home distance from hospital and hospital access were causes of major care burden.

\section{Limitations of the study}

This survey suffers from the limitations of any self-reported survey. The sampling approach sought to reach the maximum number of potential questionnaire respondents, but made it impossible to record the number aware of the questionnaire and who chose not to respond [18]. Furthermore, this online approach prevented participation by patients without any computer/internet access. Not all patients have access to the internet, are confident using a computer or use it regularly, or they may be too ill to fill in a survey. As a consequence, there may be a huge selection bias.

\section{Conclusion}

With the above limitations, this survey may be useful for healthcare providers and policy makers to improve the quality of the daily lives of VAIs. Many of the issues identified in the present article are faced by the growing community of ventilator users.

\section{Acknowledgements}

The authors thank all the ventilator users and family members who helped to develop and completed the online questionnaire to share their experiences. The ERS Task Force on Tele-Monitoring of Ventilator-Dependent Patients consisted of Nicolino Ambrosino (Volterra, Italy) and Michele Vitacca (Lumezzane, Italy) (the coordinators); Felip Burgos (Barcelona, Spain), Michael Dreher (Aachen, Germany), Joan Escarrabill (Barcelona, Spain), Brigitte Fauroux (Paris, France), Miguel Goncalves (Porto, Portugal), Valentina Isetta (Barcelona, Spain), Michael Kampelmacher (Utrecht, The Netherlands), Stefano Mazzoleni (Pisa, Italy), Bengt Midgren (Uppsala, Sweden), Susana Pinto (Lisbon, Portugal), Anita Simonds (London, UK), Giuseppe Turchetti (Pisa, Italy), Guido Vagheggini (Volterra, Italy) and Joao Carlos Winck (Porto, Portugal).

\section{References}

1 Lloyd-Owen SJ, Donaldson GC, Ambrosino N, et al. Patterns of home mechanical ventilation use in Europe: results from the Eurovent survey. Eur Respir J 2005; 25: 1025-1031.

2 Rose L, McKim DA, Katz SL, et al. Home mechanical ventilation in Canada: a national survey. Respir Care 2015; 60: 695-704. 
3 Garner DJ, Berlowitz DJ, Douglas J, et al. Home mechanical ventilation in Australia and New Zealand. Eur Respir J 2013; 41: 39-45.

4 Escarrabill J, Tebé C, Espallargues M, et al. Variability in home mechanical ventilation prescription. Arch Bronconeumol 2015; 51: 490-495.

5 Kohnlein T, Windisch W, Kohler D, et al. Non-invasive positive pressure ventilation for the treatment of severe stable chronic obstructive pulmonary disease: a prospective, multicentre, randomised, controlled clinical trial. Lancet Respir Med 2014; 2: 698-705.

6 MacIntyre EJ, Asadi L, Mckim DA, et al. Clinical outcomes associated with home mechanical ventilation: a systematic review. Can Respir J 2016; 2016: 6547180.

7 King AC. Long-term home mechanical ventilation in the United States. Respir Care 2012; 57: 921-930.

8 Farre R, Lloyd-Owen SJ, Ambrosino N, et al. Quality control of equipment in home mechanical ventilation: a European survey. Eur Respir J 2005; 26: 86-94.

9 Chatwin M, Heather S, Hanak A, et al. Analysis of home support and ventilator malfunction in 1,211 ventilator-dependent patients. Eur Respir J 2010; 35: 310-316.

10 Nava S, Sturani C, Hartl S, et al. End-of-life decision-making in respiratory intermediate care units: a European survey. Eur Respir J 2007; 30: 156-164.

11 Brooks D, King A, Tonack M, et al. User perspectives on issues that influence the quality of daily life of ventilator-assisted individuals with neuromuscular disorders. Can Respir J 2004; 11: 547-554.

12 Vitacca M, Grassi M, Barbano L, et al. Last 3 months of life in home-ventilated patients: the family perception. Eur Respir J 2010; 35: 1064-1071.

13 Evans R, Catapano MA, Brooks D, et al. Family caregiver perspectives on caring for ventilator-assisted individuals at home. Can Respir J 2012; 19: 373-379.

14 Ambrosino N, Vitacca M, Dreher M, et al. Tele-monitoring of ventilator-dependent patients: a European Respiratory Society Statement. Eur Respir J 2016; 48: 648-663.

15 Anderson CS, Linto J, Steward-Wynne E. A population-based assessment of the impact and burden of caregiving for long-term stroke survivors. Stroke 1995; 26: 843-849.

16 Hunt CK. Concepts in caregiver research. J Nurs Scholar 2003; 35: 27-32.

17 Bowling A. Research Methods in Health: Investigating Health and Health Services. 4th Edn. Maidenhead, Open University Press, 2014

18 Shaghaghi A, Bhopal RS, Sheikh A. Approaches to recruiting "hard-to-reach" populations into research: a review of the literature. Health Promot Perspect 2011; 1: 86-94.

19 Masefield S, Powell P, Vitacca M, et al. Calling for comfort: the unmet needs of European home ventilator users. RED Guide 2016-2017; 32-37.

20 Masefield S, Vitacca M, Ambrosino N. The unmet needs of home mechanical ventilator users in Europe: the patients' perspective. Eur Respir J 2016; 48: Suppl. 60, OA3528.

21 Simonds AK. Home mechanical ventilation: an overview. Ann Am Thorac Soc 2016; 13: 2035-2044

22 Vitacca M, Barbano L, D'Anna S, et al. Comparison of five bilevel pressure ventilators in patients with chronic ventilatory failure: a physiologic study. Chest 2002; 122: 2105-2114.

23 American Thoracic Society. Respiratory care of the patient with Duchenne muscular dystrophy: ATS consensus statement. Am J Respir Crit Care Med 2004; 170: 456-465.

24 Harris DR. Aging Sourcebook: Basic Information on Issues Affecting Older Americans, Including Demographic Trends, Social Security, Medicare, Estate Planning, Legal Rights, Health and Safety, Elder Care Options, Retirement Lifestyle Options, and End of Life Issues. Detroit, Omnigraphics, 1998.

25 Chio A, Gauthier A, Calvo A, et al. Caregiver burden and patients' perception of being a burden in ALS Neurology 2005; 64: 1780-1782.

26 Struik FM, Sprooten RT, Kerstjens HA, et al. Nocturnal non-invasive ventilation in COPD patients with prolonged hypercapnia after ventilatory support for acute respiratory failure: a randomised, controlled, parallel-group study. Thorax 2014; 69: 826-834.

27 Clinical indications for non invasive positive pressure ventilation in chronic respiratory failure due to restrictive lung disease, COPD, and nocturnal hypoventilation: a consensus conference report. Chest 1999; 116: 521-534.

28 Windisch W, Walterspacher S, Siemon K, et al. Guidelines for non-invasive and invasive mechanical ventilation for treatment of chronic respiratory failure. Pneumologie 2010; 64: 640-652.

29 McKim DA, Road J, Avendano M, et al. Home mechanical ventilation: a Canadian Thoracic Society clinical practice guideline. Can Respir J 2011; 18: 197-215.

30 Global Initiative for Chronic Obstructive Lung Disease. GOLD Strategy for Diagnosis, Management, and Prevention of COPD - 2016. http://goldcopd.org/global-strategy-diagnosis-management-prevention-copd-2016/ Date last accessed: December 2016.

31 Crimi C, Noto A, Princi P, et al. Domiciliary non-invasive ventilation in COPD: an international survey of indications and practices. COPD 2016; 13: 483-490.

32 Vitacca M, Escarrabill J, Galavotti G, et al. Home mechanical ventilation patients: a retrospective survey to identify level of burden in real life. Monaldi Arch Chest Dis 2007; 67: 142-147. 